\title{
Modified fruit pericarp as an effective biosorbent for removing azo dye from aqueous solution: study of adsorption properties and mechanisms
}

\author{
Jinzhen Ma ${ }^{1}$, Liyuan $\mathrm{Hou}^{2}$, Ping $\mathrm{Li}^{1,3,4^{\dagger}}$, Shumin Zhang ${ }^{1}$, Xiangyu Zheng ${ }^{1,3,4}$ \\ ${ }^{1}$ School of Environment and Energy, South China University of Technology, Guangzhou 510006, China \\ ${ }^{2}$ Department of Chemistry, SUNY College of Environmental Science and Forestry Syracuse, Syracuse, NY 13210, USA \\ ${ }^{3}$ The Key Laboratory of Pollution Control and Ecosystem Restoration in Industry Clusters of Ministry of Education, Guangzhou 510006, China \\ ${ }^{4}$ The Key Laboratory of Environmental Protection and Eco-Remediation of Guangdong Regular Higher Education Institutions, Guangzhou 510006, China
}

\begin{abstract}
To explore cheap, easily available and high adsorption performance bioadsorbent is still an important task for azo dye pollution control. In this study, the Methyl orange (MO) adsorption capacity by a novel bioadsorbent obtained from lychee and longan pericarps via simple modification was investigated. Prepared pericarps were modified by PEI at $30^{\circ} \mathrm{C}$ and $65^{\circ} \mathrm{C}$, which improved the adsorption performance confirmed by batch adsorption experiments. The characteration of modified pericarps by X-ray diffraction, scanning electron microscopy and zeta potential indicated that the enhanced adsorption performance may be due to the abundant amines and imines and stronger electropositivity. The maximum adsorption capacity $\left(349.37 \mathrm{mg} / \mathrm{g}\right.$ ) was observed for LC@PEI-65 at $45^{\circ} \mathrm{C}$ and $\mathrm{pH} 4$. Freundlich isotherm model fitted pretty well with the isotherm experiment data, and the isotherm experimental data were preferably described by pseudo-second order model indicating the chemical adsorption process, and the intra-particle diffusion also involved in the adsorption process. Characterization and adsorption tests suggested electrostatic interaction played a key role in $\mathrm{MO}$ removal, accompanied by intermolecular hydrogen bond, $\pi$ - $\pi$ dispersion interaction and pore filling collectively. The present study show that the cost-effective PEI modified pericarps could possess a hopeful application for azo dye removal from wastewater.
\end{abstract}

Keywords: Azo dye, Longan pericarp, Lychee pericarp, Methyl orange adsorption, Polyethyleneimine modification

\section{Introduction}

Water pollution caused by organic pollutants has become a serious environmental issue worldwide, and dyes is one of the most common organic pollutants [1, 2]. Dyes are widely used in paper, textile, pharmaceutical and leather industries [3]. Particularly, Azo dyes are the most widely used type of organic dyes accounting for $70 \%$ of all synthetic dyes which are persistent and even carcinogenic [4]. Methyl orange (MO, $\mathrm{C}_{14} \mathrm{H}_{14} \mathrm{~N}_{3} \mathrm{O}_{3} \mathrm{~S}$ ) is a typical azo dye and its molecular structure contains only one azo group $(-\mathrm{N}=\mathrm{N}-)$. Without proper treatment, the discharged azo dye would remain in the environment for a long period of time, which may cause harm to the living organisms, such as tachycardia, vomiting, jaundice, quadriplegia, and tissue necrosis because of the production of carcinogenic aromatic amines by azo dyes decomposition under certain conditions $[5,6]$. Therefore, technologies for removing azo dye from wastewater are urgent needed.

Up to now, various technologies have been used to remove dyes from wastewater, which can be divided into chemical methods, biological methods and physical methods [7]. Chemical methods such as advanced oxidation, electrochemical, ozone oxidation and photochemical methods can remove the pollutants rapidly and efficiently [8]. However, the costs of investment and operation were high due to the large amount consumption of chemical reagents and electric energy, which make it unattractive for the current commercial application [9, 10]. Biological methods including algae degradation, anaerobic and aerobic biodegradation and phytoremediation are simple and eco-friendly, but bioreactors require
${ }^{\dagger}$ Corresponding author

E-mail: pli@scut.edu.cn

Tel: +86-20-39380568

ORCID: 0000-0003-1072-4160 
large space and generate excess sludge which needs disposal. Besides, the chemical structure of most azo dyes is complex and stable resulting in unsatisfactory biodegradation and removal efficiency [11, 12]. Comparing to other traditional technologies, adsorption is one of the most promising methods due to its inexpensiveness, simplicity and effectiveness [13].

Up to now, activated carbon materials, polymeric resins, zeolites, clays and biomaterials have been applied as adsorbents to remove dyes [14-18]. Among these adsorbents, commercial adsorbents such as activated carbon, zeolite and chitosan are still limited by their high cost. Meanwhile, biomass-based adsorbents have attracted more attention due to their widespread availability, low-cost, and biodegradability. Gilbert K [19] reported the use of coffee husks to remove toxic crystal violet dye from wastewater (the dye uptake was $2.02 \mathrm{mg} / \mathrm{g}$ ). Bulgariu [20] demonstrated efficient removal of eosin yellow dye from wastewater by using sugarcane bagasse as adsorbent (with adsorption capacity of $58.47 \mathrm{mg} / \mathrm{g}$ ). Cengiz [21] utilized Posidonia oceanica as a low cost biomaterial to remove astrazon red from wastewater (the maximum adsorption capacity reached $68.97 \mathrm{mg} / \mathrm{g}$ ). Argun ME [22] described the removal of Reactive Blue 114 dye from aqueous solutions by using pomelo peel (maximum adsorption capacity was obtained as $16 \mathrm{mg} / \mathrm{g}$ ). Singh [23] reported waste banana peel could remove $81.07 \%$ rhodamine-B dye from aqueous streams. Temesgen $\mathrm{F}$ [24] reported the ability of orange peel and banana peel powder to adsorb reactive red dye were $3.97 \mathrm{mg} / \mathrm{g}$ and 3.89 $\mathrm{mg} / \mathrm{g}$, respectively. However, so far, there are few report on the application of lychee and longan pericarp to azo dye pollution adsorption.

As an alternative potential bioadsorbent, lychee and longan pericarp have received increasing attention in recent years. The capacity of heavy metal removal by lychee pericarp has been investigated and showed an excellent remove capacity [25, 26]. Researches have signified that lychee and longan pericarp contains a large amount of cellulose, lignin, sugar and fat, and there are a variety of functional groups, such as carboxyl, hydroxyl, carbonyl and amide functional groups on its surface, which showing potential value for dyes adsorption [27]. Besides, China is the major production area for lychee and longan with accounting for $70 \%$ and $59.7 \%$ of world production respectively [28, 29]. A mass of waste pericarps was discarded from the juice industry [30]. Waste pericarps would decompose and cause mosquito breeding and disease transmission without proper treatment threated to public health eventually. Therefore, two ecological problems would be solved with using lychee and longan pericarps as adsorbents: utilization of pericarp wastes and removal of azo dye from wastewater [31].

The direct application of pericarps for dyes removal was hindered by their low adsorption capacity. Based on this background, original pericarps with finite adsorption capacities are essential to be chemically modified. Polyethyleneimine (PEI) is a branched cationic polymer which has a good adsorption capacity of many anionic compounds due to its abundant primary and secondary amine functional groups [32]. It cannot applied directly as an adsorbent due to its high water solubility [33]. Nevertheless, amine functional groups could be grafted onto some matrix materials that are rich in oxygen-containing functional groups (such as $\mathrm{OH}$, - $\mathrm{COOH}$ and -CHO) easily [34]. The introduction of nitrogen-containing functional groups on pericarp wastes could improve their adsorption efficiency and the removal ability of dye molecules.

This work aimed to develop a low-cost, high-efficiency, and recyclable bioadsorbent by modifying lychee and longan pericarp with a simple, short time-consuming, low cost and environmental method. We firstly reported the potential of PEI modified lychee and longan pericarps for azo dye removal. The prepared bioadsorbents were further characterized by XRD, FTIR, SEM, EDS and zeta potential analysis. Effects of operating parameters including the adsorbent dosage, $\mathrm{pH}$, contact time and initial pollutant concentration were investigated by batch experiments. In addition, the kinetic and isotherm were studied and the mechanisms were deduced. This study provided theoretical foundation and technical reference for the resource utilization of pericarp wastes and azo dye pollution control in wastewater.

\section{Materials and Methods}

\subsection{Synthesis of PEI Modified Pericarps}

Lychee (LC) and longan pericarps (LG) were collected from a fruit market in Guangzhou. Then, they were washed with tap water and deionized water for several times to remove the surface impurities and ground into powder by high-speed grinder after drying at $80^{\circ} \mathrm{C}$. The original unmodified lychee pericarp (NLP) and unmodified longan pericarp (NLG) were obtained with passing the 60-mesh sieve, respectively.

For the preparation of modified pericarps, 2 g pericarp powder, $4 \mathrm{~mL} \mathrm{50 \%} \mathrm{glutaraldehyde} \mathrm{and} 140 \mathrm{~mL}$ deionized water were mixed in a $500 \mathrm{~mL}$ conical flask, and then stirred for $30 \mathrm{~min}$ at room temperature. Following this operation, $0.6 \mathrm{~g}$ PEI was added to the mixture and stirred at $200 \mathrm{rpm}$ for $6 \mathrm{~h}$ at $30^{\circ} \mathrm{C}$ and $65^{\circ} \mathrm{C}$, respectively. Subsequently, the mixture was filtered and washed with deionized water for three times to remove the excess PEI and glutaraldehyde. Finally, the materials were oven-dried at $50^{\circ} \mathrm{C}$ for $24 \mathrm{~h}$. The modified lychee pericarp with PEI prepared at $30^{\circ} \mathrm{C}$ and $65^{\circ} \mathrm{C}$ were named as LC@PEI-30 and LC@PEI-65, respectively. Correspondingly, the PEI modified longan pericarp prepared at $30^{\circ} \mathrm{C}$ and $65^{\circ} \mathrm{C}$ were christened LG@PEI-30 and LG@PEI-65, respectively. The prepared pericarps were stored in a clean, dry, air-tight container before next use.

\subsection{Characterization of Pericarps}

To observe the crystal structure and physical properties of pericarps, X-ray diffraction (XRD, D8 ADVANCE Bruker, Germany) were investigated in the range of $2 \theta=10^{\circ} \sim 60^{\circ}$. FTIR Spectrophotometer (FTIR, Nicolet iS10, Thermo) was performed for ascertaining the surface functional groups. Meanwhile, zeta potential analyzer (Zetasizer Nano ZS, Malvern, UK) was applied to understand the surface charge. Scanning electron microscopy (SEM, Merlin, Carl Zeiss, Germany) was used to analyze the surface morphology and pore size of the pericarp before and after modification. Main components of the material 
surface were determined by energy-dispersive X-ray spectroscopy (EDS).

\subsection{MO Concentration Determination}

MO stock solution was prepared by adding $1 \mathrm{~g}$ MO to $1,000 \mathrm{~mL}$ deionized water. The calibration curve was obtained based on a series of standard solutions ranged from $0.5 \mathrm{mg} / \mathrm{L}$ to $15 \mathrm{mg} / \mathrm{L}$. Following batch adsorption experiments, the MO concentration of the filtrate through a $0.45 \mu \mathrm{m}$ membrane was measured by an ultraviolet-visible spectrophotometer (UV-1800, Shimadzu, Japan) with a wavelength of $464 \mathrm{~nm}$. Subsequently, the MO concentration was calculated based on the calibration curve.

\subsection{Batch Adsorption Experiments}

Effect of contact time: $10 \mathrm{mg}$ pericarps and $50 \mathrm{~mL}$ MO solution $(20 \mathrm{mg} / \mathrm{L})$ with $\mathrm{pH} 4.0$ were mixed in a flask and agitated on a rotary oscillator $(200 \mathrm{rpm})$ at $30^{\circ} \mathrm{C}$ for $24 \mathrm{~h} .10 \mathrm{~mL}$ solution samples were collected at a certain time interval for researching the relationship between adsorption capacity and contact time. The MO concentration was detected by spectrophotometry after the sample filtered through $0.45 \mu \mathrm{m}$ membranes.

Effect of initial concentration: The initial concentration oscillated between $5 \mathrm{mg} / \mathrm{L}$ and $250 \mathrm{mg} / \mathrm{g}$ aiming to study the influence of contact time on MO adsorption. $10 \mathrm{mg}$ adsorbents were mixed with $50 \mathrm{~mL} \mathrm{MO}$ solutions with different concentrations $(\mathrm{pH}=$ 4.0). The mixture was shaken at $30^{\circ} \mathrm{C}$ and solution samples were collected after $24 \mathrm{~h}$.

Effect of temperature: With a purpose to exploring the influence of temperature on the adsorption process, $10 \mathrm{mg}$ adsorbents was added into $50 \mathrm{~mL} \mathrm{MO}$ solution $(\mathrm{pH}=4.0)$ with an initial concentration of $30 \mathrm{mg} / \mathrm{L}$. The mixture was shaken at three temperatures $\left(30^{\circ} \mathrm{C}, 45^{\circ} \mathrm{C}\right.$, and $\left.60^{\circ} \mathrm{C}\right)$ for $24 \mathrm{~h}$ until equilibrium, and the solution samples were collected to determine MO concentration.

Effect of pH: $10 \mathrm{mg}$ LC@PEI-65 was added into $100 \mathrm{~mL} \mathrm{MO}$ solution in the concentration of $10 \mathrm{mg} / \mathrm{L}$. The mixture was adjusted to cover the $\mathrm{pH}$ range 3-10 and placed in an oscillating shaker at $30^{\circ} \mathrm{C}$. After $24 \mathrm{~h}$, solution samples were collected for $\mathrm{MO}$ measurement.

Effect of adsorbent dosage: To study the effect of the adsorbent dosage on MO removal, the dosage of LC@PEI-65 was varied from 0.05 to $0.6 \mathrm{~g} / \mathrm{L} .50 \mathrm{~mL}$ of $\mathrm{MO}$ solution containing different initial concentrations $(20 \mathrm{mg} / \mathrm{L}$ and $30 \mathrm{mg} / \mathrm{L})$ at $\mathrm{pH} 4$ was added with calculated amount of LC@PEI-65. The mixture was agitated in the constant temperature shaker for $24 \mathrm{~h}$ at $30^{\circ} \mathrm{C}$ with a shaking speed of $200 \mathrm{rpm}$. After $24 \mathrm{~h}, 10 \mathrm{~mL}$ solution samples were collected for MO measurement.

Effect of salt concentration: Effects of $\mathrm{NaCl}$ and $\mathrm{CaCl}_{2}$ ranging from $0 \mathrm{~mol} / \mathrm{L}$ to $0.2 \mathrm{~mol} / \mathrm{L}$ on the $\mathrm{MO}$ adsorption were investigated. In the experiment, the adsorption reaction of LC@PEI-65 (10 mg) and MO solution $(50 \mathrm{~mL} ; 30 \mathrm{mg} / \mathrm{L} ; \mathrm{pH}=4.0$ ) was conducted in the oscillator for $24 \mathrm{~h}$. After adsorption, solution samples were collected for MO measurement.

In this series of adsorption batch experiments, the $\mathrm{pH}$ of each solution was adjusted by $0.1 \mathrm{M} \mathrm{HCl}$ and $\mathrm{NaOH}$.

The removal efficiency $\eta(\%)$ and adsorption capacity $q_{e}(\mathrm{mg} / \mathrm{g})$ were calculated according to Eq. (1) and Eq. (2), respectively.

$$
\begin{gathered}
\eta=\frac{C_{0}-C_{e}}{C_{0}} \times 100 \% \\
q_{e}=\frac{\left(C_{0}-C_{e}\right) \times V}{m}
\end{gathered}
$$

Where $C_{0}(\mathrm{mg} / \mathrm{L})$ and $C_{e}(\mathrm{mg} / \mathrm{L})$ represent the initial and equilibrium concentrations of $\mathrm{MO}$, respectively. $V(\mathrm{~L})$ is the volume of solution and $m(\mathrm{~g})$ is the weight of adsorbents.

\subsection{Adsorption Kinetics}

The data of kinetic experiments were evaluated by the pseudo-first order (Eq. (3)), pseudo-second order (Eq. (4)), Elovich (Eq. (5)) and intra-particle diffusion models (Eq. (6)) [35, 36].

$$
\begin{gathered}
q_{t}=q_{e}\left(1-e^{-k_{1} t}\right) \\
q_{t}=k_{2} q_{e}^{2} t /\left(1+k_{2} q_{e} t\right) \\
q_{t}=\frac{1}{\beta} \ln (1+\alpha \beta t) \\
q_{t}=K_{i} t^{1 / 2}+C_{i}
\end{gathered}
$$

Where $t$ (min) is contact time, $q_{t}(\mathrm{mg} / \mathrm{g})$ and $q_{e}(\mathrm{mg} / \mathrm{g})$ represent the adsorption capacity at time $t$ and equilibrium, respectively. $k_{1}\left(\mathrm{~min}^{-1}\right)$ and $k_{2}\left(\mathrm{~g} \cdot \mathrm{mg}^{-1} \cdot \mathrm{min}^{-1}\right)$ are the rate constants for pseudo-first and pseudo-second order, respectively. $A\left(\mathrm{mg} \cdot \mathrm{g}^{-1} \cdot \mathrm{min}^{-1}\right)$ and $\beta\left(\mathrm{g} \cdot \mathrm{mg}^{-1}\right)$ represent the initial adsorption coefficient and desorption coefficient of Elovich model, respectively. $K_{i}\left(\mathrm{mg} \cdot \mathrm{g}^{-1}\right.$. $\left.\mathrm{min}^{-1}\right)$ is the intra-particle diffusion rate constant and $C_{i}(\mathrm{mg} / \mathrm{g})$ is the the boundary layer thickness. The values of $K_{i}$ and $C_{i}$ of step $i$ could be calculated from the slope and intercept of linear fitting, respectively.

\subsection{Adsorption Isotherm}

Langmuir (Eq. (7)), Freundlich (Eq. (8)), Temkin (Eq. (9)) and Dubinin - radushkevich (D-R) (Eq. (10) and Eq. (11)) models were used to evaluate the data of adsorption isotherms [37-39].

Langmuir isotherm equation:

$$
q_{e}=k_{L} q_{m} C_{e} /\left(1+k_{L} C_{e}\right)
$$

Freundlich isotherm equation:

$$
q_{e}=K_{F} C_{e}^{1 / n}
$$

Temkin isotherm equation:

$$
q_{e}=B \ln K_{T}+B \ln C_{e}
$$

Where $C_{e}(\mathrm{mg} / \mathrm{L})$ and $q_{e}(\mathrm{mg} / \mathrm{g})$ represent the MO concentration and adsorption capacity at equilibrium, respectively. $q_{m}(\mathrm{mg} / \mathrm{g})$ is the theoretical adsorption capacity of the material and $k_{L}(\mathrm{~L} / \mathrm{mg})$ represent the Langmuir constant. $K_{F}\left(\mathrm{mg}^{-1} \cdot \mathrm{L}^{-1 / \mathrm{n}} \cdot \mathrm{mg}^{-1 / \mathrm{n}}\right)$ is the Freundlich constant related to adsorption capacity and adsorption 
energy. $n$ is the heterogeneity coefficient indicating the favorability of the adsorption process. $B(\mathrm{~J} / \mathrm{mol})$ and $k_{T}(\mathrm{~L} / \mathrm{mg})$ represent the Temkin constant and the equilibrium binding constant, respectively.

D-R adsorption isotherm equations:

$$
\begin{gathered}
q_{e}=q_{m} e^{-\beta \varepsilon^{2}} \\
\varepsilon=R \operatorname{Rln}\left(1+1 / C_{e}\right)
\end{gathered}
$$

Where $\beta\left(\mathrm{mol}^{2} / \mathrm{kJ}^{2}\right)$ represent the D-R isotherm constant, $\varepsilon(\mathrm{kJ} / \mathrm{mol})$ is Polyani potential energy related to the equilibrium concentration. $R\left(8.314 \mathrm{~J} \cdot \mathrm{mol}^{-1} \cdot \mathrm{K}^{-1}\right)$ is the universal gas constant and $T(\mathrm{~K})$ represent the absolute temperature.

\subsection{Evaluation of Regeneration and Reuse}

Adsorption-desorption experiment was performed to estimate the stability and reusability of modified pericarps. Desorption of MO was achieved by choosing $0.1 \mathrm{M}$ sodium hydroxide solution as the desorption medium. The mixture of adsorbent loaded MO and $0.1 \mathrm{M}$ sodium hydroxide solution was stirred at $200 \mathrm{rpm}$ for 12 $\mathrm{h}$ at room temperature. Subsequently, the material was collected and washed by deionized water, then dried at $50^{\circ} \mathrm{C}$ for the next cycle of adsorption experiment. The whole experiment was conducted five cycles and the desorption efficiency was calculated by following Eq. (12).

$$
\begin{gathered}
\omega=\frac{\text { Amount of } M O \text { desorbed in } 0.1 M \text { sodium hydroxide solution }}{\text { Amount of } M O \text { adsorbed onto adsorbent }} \\
\qquad=\frac{C_{i} \times V_{2}}{\left(C_{0}-C_{e}\right) \times V_{1}} \times 100 \%
\end{gathered}
$$

Where $\omega$ is the desorption efficiency. $C_{0}(\mathrm{mg} / \mathrm{L})$ and $C_{e}(\mathrm{mg} / \mathrm{L})$ represent the initial and equilibrium MO solution concentration in the adsorption experiment, respectively. $C_{i}(\mathrm{mg} / \mathrm{L})$ is the MO concentration in the solution after the desorption experiment finished. $V_{1}$ is solution volume in adsorption experiment and $V_{2}$ (L) represents the volume of $0.1 \mathrm{M}$ sodium hydroxide solution applied in desorption experiment.

It should be noted that all batch adsorption experiments were conducted in triplicate and the data analysis was carried out with one-way ANOVA by SPSS-19.0 software [40].

\section{Results and Discussion}

\subsection{Modification of Pericarps}

The modification principle of PEI modified pericarps was shown in Fig. 1. Firstly, the condensation of phenol formaldehyde occurred between one or two hydroxyl groups of natural pericarps with glutaraldehyde. After PEI added in, the reaction process mainly included the following aspects: (1) Mannich reaction occurred between the aldehyde group on glutaraldehyde and the primary or secondary amines of PEI. (2) The hydroxyl groups on the pericarp were linked to the amine groups of PEI with the formation of intermolecular hydrogen bonds. (3) The carboxyl group (-COOH) on the surface of pericarp reacted with the primary amine of PEI to form an amide bond [41, 42].

The color of NLC and NLG and modified pericarps with PEI generated at different temperature was shown in Fig. S1. The appearance of NLC presented light brownish red, and the brownish red deepened after the modification at $30^{\circ} \mathrm{C}$. As for lychee pericarp modified at $65^{\circ} \mathrm{C}$, the appearance was dark brown. The color of modified longan pericarp changed from light yellow to brown red and finally to brown when the modification temperature increased to $65^{\circ} \mathrm{C}$. The change of pericarp color confirmed the occurrence of chemical modification reaction.

\subsection{Characterization of Modified Pericarps}

The crystal structure of pericarps was investigated by X-ray diffraction (Fig. 2(a) and (b)). For all adsorbents, the typical crystal peaks of type I cellulose were observed, which indicating that all adsorbents were dominantly composed of cellulose and the modification process impacted the cellulose structure slightly. The broad peaks around $15.5^{\circ}$ and $22.0^{\circ}$ correspond to the amorphous and crystalline regions of cellulose [43]. After PEI thermochemical modification, the crystalline area decreased while the amorphous area increased indicating that the modification process eliminated crystallization and the cellulose crystallinity was impacted by temperature apparently. The decrease of crystalline area indicated the exposure of more hydroxyl functional group. More amino and imino groups was introduced into pericarps due to the reaction of hydroxyl and PEI, further leading stronger interaction between modified pericarps and MO molecules.

FTIR spectra provides detailed information about surface functional groups. The FTIR spectra of NLC, LC@PEI-30, LC@PEI-65,

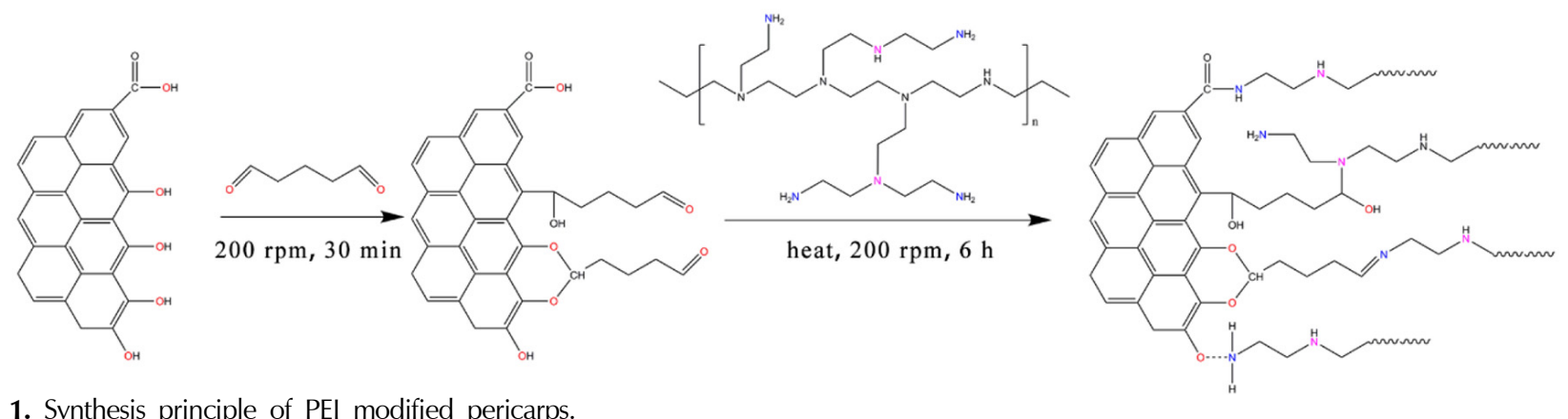

Fig. 1. Synthesis principle of PEI modified pericarps. 

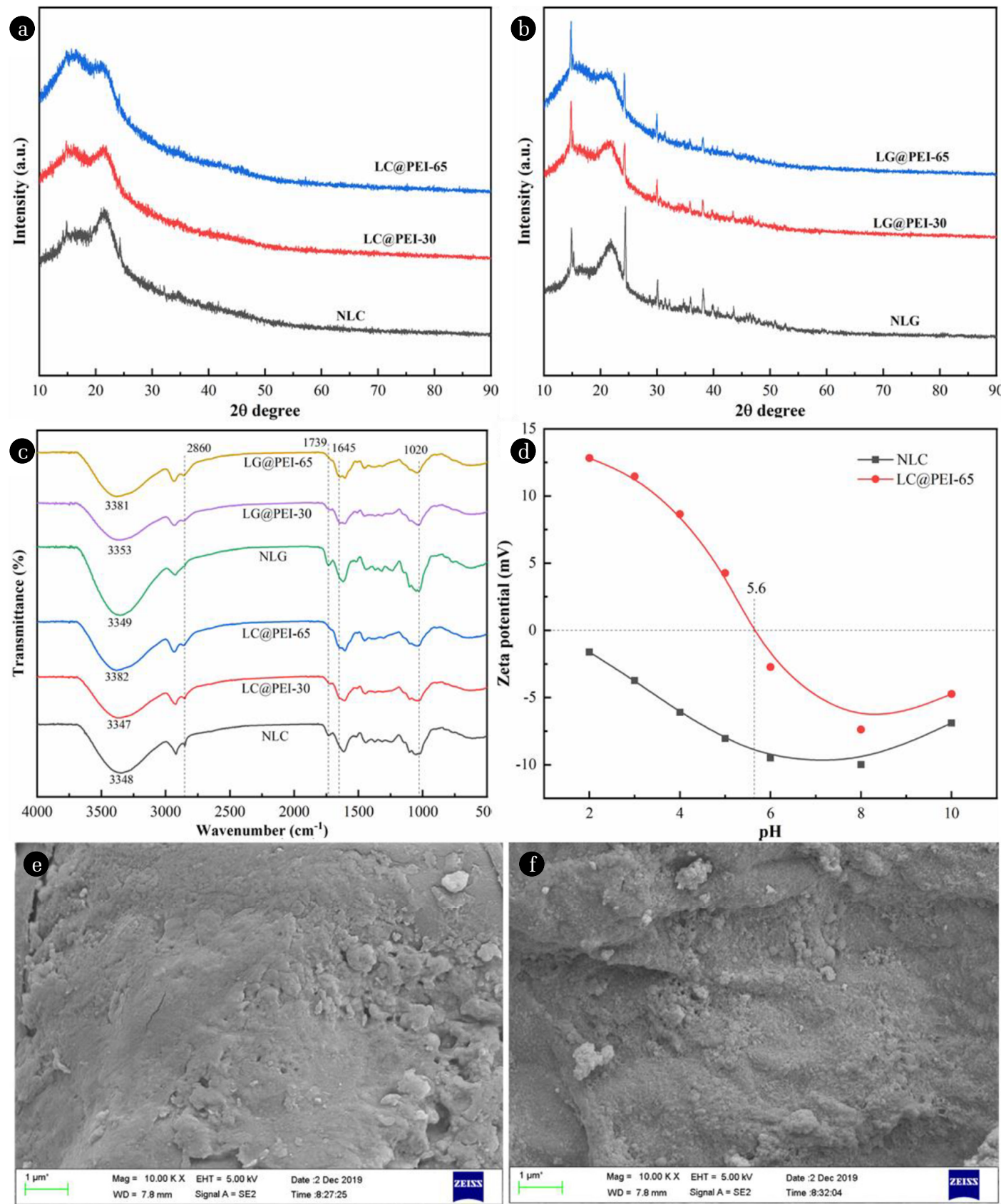

Fig. 2. XRD patterns of lychee pericarp before and after modofocation (a) and longan pericarp before and after modofocation (b), FTIR spectra of bioadsorbents (c), Zeta potential of NLP and LP@PEI-65 (d), SEM micrographs of the NLP (e) and LP@PEI-65 (f).

NLG, LG@PEI-30 and LG@PEI-65 were shown in Fig. 2(c). The large scale vibration around $3,000-3,500 \mathrm{~cm}^{-1}$ indicated the presence of $-\mathrm{OH}$ [44]. The band near $1,739 \mathrm{~cm}^{-1}$ represented the $\mathrm{C}=\mathrm{O}$ stretching vibration in $-\mathrm{COOH}$ and $-\mathrm{COOR}$. The band observed at 1,020 $\mathrm{cm}^{-1}$ corresponded to the asymmetric stretching vibration of C-O-C. The presence of these absorption peaks confirmed the existence of oxygen-containing functional groups (such as hydroxyl groups, carboxyl groups, aldehyde groups, and ethers) on the NLC and NLG. After PEI modification, the $\mathrm{C}=\mathrm{O}$ peak was significantly weakened indicating that cross-linking reaction occurred between -COOH and PEI during the modification process. The peak near $1,645 \mathrm{~cm}^{-1}$ and $2,860 \mathrm{~cm}^{-1}$ were attributed to the stretching vibration of $-\mathrm{NH}_{2}$ and the antisymmetric angle of $\mathrm{NH}_{3}{ }^{+}$, respectively, which further confirmed that the PEI modification introduced additional amino and imino groups into lychee and longan pericarps [25, 45].

Zeta potential is closely related to adsorption capacity. As shown in Fig. 2(d), the zeta potential values of LC@PEI-65 were always 
higher than NLC in the $\mathrm{pH}$ range of 2-10, indicating that the thermal modification with PEI improved the positive electricity of pericarp. The isoelectric point $\left(\mathrm{pH}_{\mathrm{pzc}}\right)$ of LC@PEI-65 is 5.6 suggesting that LC@PEI-65 is positively charged due to the protonation of amines and imines with a $\mathrm{pH}$ less than 5.6. When the $\mathrm{pH}$ is more than 5.6, $\mathrm{OH}^{-}$in the solution would combine with LC@PEI-65 resulting in the negative surface charge. The above results indicated that the removal of MO dye by LC@PEI-65 was more favorable at lower pH values. The results suggested that LC@PEI-65 possessed stronger electropositivity than NLC because of amines and imines, which confirmed that electrostatic interaction plays a role in the adsorption of $\mathrm{MO}$ at least in part.

The microstructure of NLP and LP@PEI-65 were revealed by SEM images (Fig. 2(e) and (f)). The unmodified lychee pericap was smooth and tidy without pore structures. In contrast, LC@PEI-65 presented a ridgy, clustered and scabrous surface, indicating a chemical reaction occurred on the surface of the lychee pericarp. In addition, the EDS analysis was shown in Table S1. The N content increased from $1.61 \%$ to $6.10 \%$ after thermal modification with PEI, clearly suggesting that amine and imino groups were successfully introduced into the surface of lychee pericarp. Compared with LC@PEI-65, LC@PEI-65-MO contanins more N proving the successful adsorption of MO.

\subsection{Effects of Parameters on Azo Dye Adsorption}

\subsubsection{Contact time}

From Fig. 3(a), NLC and NLG reached the adsorption equilibrium in the first 10 minutes due to their poor adsorption performance. As for modified pericarps, the adsorption capacity increased sharply due to the abundant adsorption sites [46, 47]. Subsequently, the slow increase was observed due to the decrease of available binding sites. Adsorption finally reached equilibrium when almost all adsorption sites were occupied. It was observed that LC@PEI-30, LC@PEI-65, LG@PEI-30 and LG@PEI-65 reached adsorption equilibrium at $12 \mathrm{~h}, 8 \mathrm{~h}, 6 \mathrm{~h}$ and $4 \mathrm{~h}$, respectively. The faster equilibrium suggested that the better adsorption performance of modified pericarps due to the enhancement of binding affinity by PEI thermochemical modification. The influence of contact time for MO adsorption by LC@PEI-65 at different initial concentration was further investigated and the result was shown in Fig. 3(b). The time required for equilibrium increased from $1 \mathrm{~h}$ to $16 \mathrm{~h}$ with MO initial concentration rose from $10 \mathrm{mg} / \mathrm{L}$ to $50 \mathrm{mg} / \mathrm{L}$ due to the greater mass transfer diffusion resistance.

\subsubsection{Initial concentration}

The initial MO concentration played an important role in the adsorption process. The available adsorption sites were certain for same mass pericarps adsorbent. A larger concentration gap between the adsorbents and MO appeared with the increase of MO concentration which resulted greater mass transfer driving force. Eventually, higher adsorption capacity obtained. As the initial MO concentration increased from $10 \mathrm{mg} / \mathrm{L}$ to $240 \mathrm{mg} / \mathrm{L}$, the adsorption capacity of LC@PEI-30, LC@PEI-65, LG@PEI-30 and LG@PEI-65 raised from $49.85 \mathrm{mg} / \mathrm{g}, 51.55 \mathrm{mg} / \mathrm{g}, 46.33 \mathrm{mg} / \mathrm{g}$ and $50.70 \mathrm{mg} / \mathrm{g}$ to $257.77 \mathrm{mg} / \mathrm{g}, 349.37 \mathrm{mg} / \mathrm{g}, 242.85 \mathrm{mg} / \mathrm{g}$ and 321.68 mg/g, respectively (Fig. 3(c)). These results suggested that the initial
MO concentration was an important driving force for MO molecules to overcome the mass transfer resistance between the water phase and the solid phase [48].

\subsubsection{Temperature}

The adsorption capacity of modified pericarps at different temperature $\left(30^{\circ} \mathrm{C}, 45^{\circ} \mathrm{C}\right.$ and $\left.60^{\circ} \mathrm{C}\right)$ was investigated in this study. It was observed that the adsorption capacity of modified pericarps increased firstly and then decreased with (Fig. 3(d)). Since temperature affects the diffusion of dye molecules both in the boundary layer on the modified pericarps and in the adsorbent channel [49], the adsorption performance improved due to the higher temperature accelerated the diffusion of MO molecules [50]. However, the weakening effect of temperature on electrostatic attraction became more obvious with temperature further increased, resulting in the dropping of adsorption capacity [51]. The optimum temperature is $45^{\circ} \mathrm{C}$ for the MO adsorption by LC@PEI-65.

\subsection{4. $\mathrm{pH}$}

The $\mathrm{pH}$ is one of the critical factors in the adsorption process. Both the contaminant speciation and surface properties of adsorbents were influenced by $\mathrm{pH}$. As shown in Fig. 3(e), the removal efficiency and adsorption capacity increased firstly and then decreased sharply with the $\mathrm{pH}$ ranged from 3 to 10 . The removal efficiency of LC@PEI-65 for MO was above 85\% when the pH ranged from 3 to 6 , which was attributed to the strongly electrostatic interaction between $\mathrm{MO}$ and the protonation of amine and imine groups of LC@PEI-65 at low pH. The isoelectric point $\left(\mathrm{pH}_{\mathrm{pzc}}\right)$ of LC@PEI-65 is 5.6 indicating the adsorbent surface has a positive charge when $\mathrm{pH}<5.6$. In addition, the dissociation constant (pKa) of $\mathrm{MO}$ is 3.46 meaning $\mathrm{MO}$ molecules predominantly existed as cations at $\mathrm{pH}<3.46$ and anions at $\mathrm{pH}>3.46$ [52]. Hence, the electrostatic attraction between MO and LC@PEI-65 was strongest between $\mathrm{pH} 3.46$ and 5.6. When $\mathrm{pH}$ lower than 3.46, $-\mathrm{SO}_{3}^{-}$of the MO molecules combined with the high concentration of $\mathrm{H}^{+}$ to form $-\mathrm{SO}_{3} \mathrm{H}$, resulting in the decreasing of electrostatic attraction between the LC@PEI-65 and MO molecules. At $\mathrm{pH}>5.6$, the amine groups deprotonated gradually, the adsorption decreased with the increasing $\mathrm{pH}$ due to the amplified electrostatic repulsion [53]. If the electrostatic interaction is the only mechanism, the adsorption should be difficult to observe when the $\mathrm{pH}$ was greater than 6 and the effect of $\mathrm{pH}$ on adsorption should be larger than that observed [54]. Thus, hydrogen bonds maybe occur between MO and negative LC@PEI-65 under high pH conditions, which is consequently weaker than electrostatic interaction and resulted the decrease of adsorption capacity [55].

\subsubsection{Pericarp dosage}

As shown in Fig. 3(f), the removal efficiency of MO by LC@PEI-65 increased with the increase of adsorbent amount due to the greater numbers of adsorption active sites and increased adsorbent surface area provided by added LC@PEI-65. However, the adsorption capacity dropped with higher amount of LC@PEI-65. This mainly due to more empty active sites exited inhibiting the effective utilization of LC@PEI-65, and the aggregation and stacks of adsorbents further resulted the waste of adsorption active sites [56]. Thus, For the effectively removal of MO and saving adsorbents, the optimal amount of modified pericarp was 

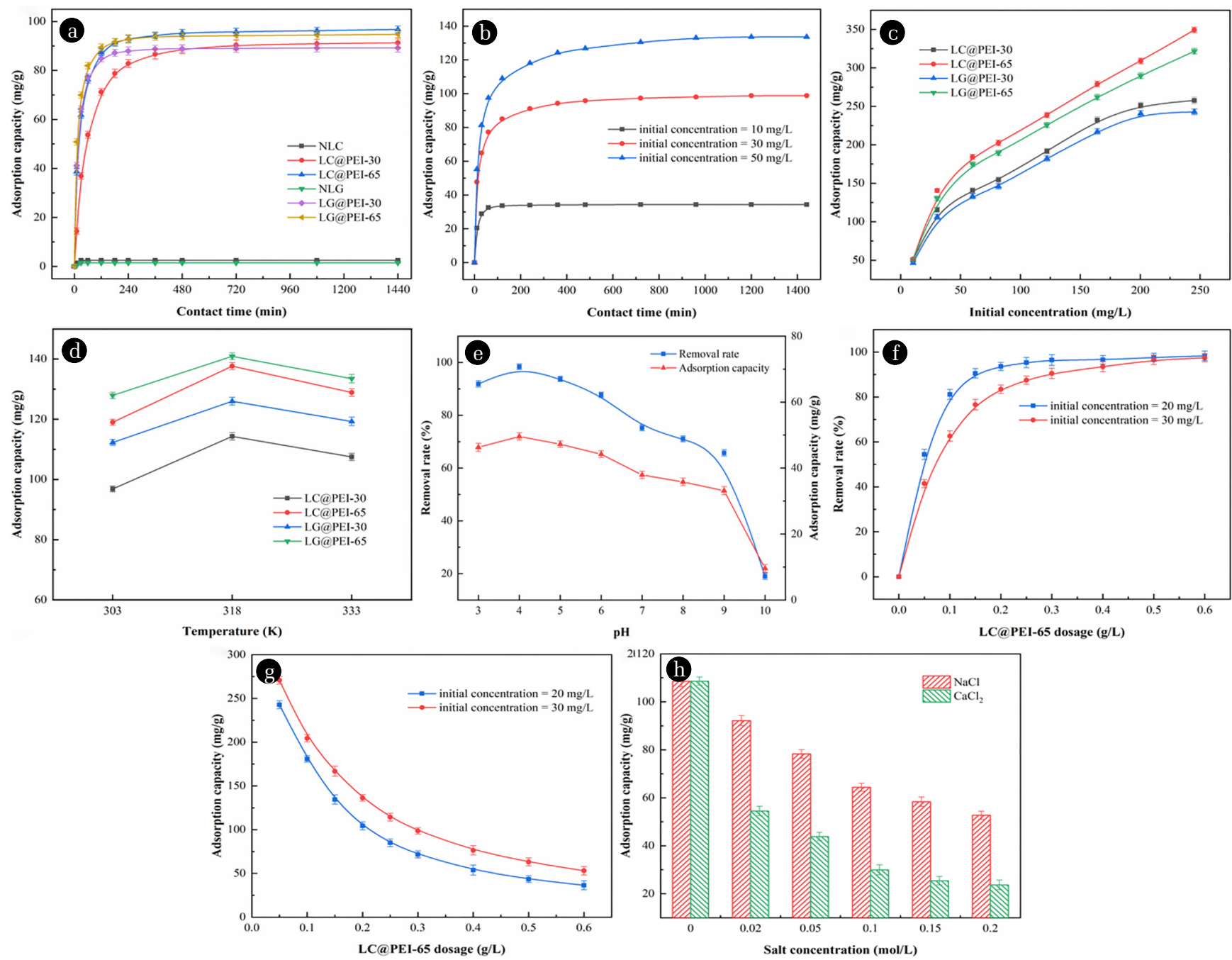

Fig. 3. Effect of $(\mathrm{a}, \mathrm{b})$ contact time, (c) initial concentration, (d) temperature on the removal of $\mathrm{MO}$ onto modified pericarps and (e) pH, (f,g) adsorbent dosage, (h) salt concentration on MO adsorption capacity of LC@PEI-65.

$0.2 \mathrm{~g} / \mathrm{L}$ and $0.5 \mathrm{~g} / \mathrm{L}$ at the initial concentrations of $20 \mathrm{mg} / \mathrm{L}$ and $30 \mathrm{mg} / \mathrm{L}$, respectively.

\subsubsection{Salt concentration}

The adsorption capacity showed a significant decreasing trend when the salt concentration increased from 0 to $0.1 \mathrm{~mol} / \mathrm{L}$ (Fig. 3(h)) (One way ANOVA, $\mathrm{P}<0.05$ ). This result indicated that the adsorption process was closely related to the salt concentration [57]. This phenomenon was due to the competition between $\mathrm{Cl}^{-}$and MO for active sites on modified pericarps, resulting in a negative effect on the electrostatic attraction. As such, the adsorption capacity of LC@PEI-65 for MO decreased from $108.62 \mathrm{mg} / \mathrm{g}$ to $64.40 \mathrm{mg} / \mathrm{g}$ as the $\mathrm{NaCl}$ concentration increased from $0 \mathrm{~mol} / \mathrm{L}$ to $0.1 \mathrm{~mol} / \mathrm{L}$. Furthermore, the adsorption capacity of LC@PEI-65 was only $29.98 \mathrm{mg} / \mathrm{g}$ when the concentration of $\mathrm{CaCl}_{2}$ reached $0.1 \mathrm{~mol} / \mathrm{L}$. This phenomenon could be accounted the presence of $\mathrm{Na}^{+}$and $\mathrm{Ca}^{2+}$ ions with high ionic strength disputed the electrostatic interactions and $\pi-\pi$ dispersion interaction between
MO and LC@PEI-65 [58]. However, slowly reduction of adsorption capacity was observed at a high $\mathrm{Ca}^{2+}$ concentration over $0.1 \mathrm{~mol} / \mathrm{L}$, indicating that there are maybe other adsorption mechanisms between PEI modified pericarps and MO, which the residual interaction may be intermolecular hydrogen bonds and Van der Waals forces [59].

\subsection{Adsorption Kinetics Evaluation}

The adsorption kinetics was applied to predict the potential adsorption mechanism, reaction pathway and the reaction time for equilibrium. Here, we applied three kinetic models to fit our data (Fig. 4(a)-(c) and Table S2). The correlation coefficients of pseudo-first order kinetic model for NLC and NLG were 0.995 and 0.951 (One way ANOVA, $\mathrm{P}<0.05$ ), respectively, which higher than other models. The pseudo-first order kinetic model indicates that the physical adsorption behavior plays the main role in the adsorption process. Thus, the MO adsorption by unmodified pericarps was mainly a physical process. As for modified pericarps, 

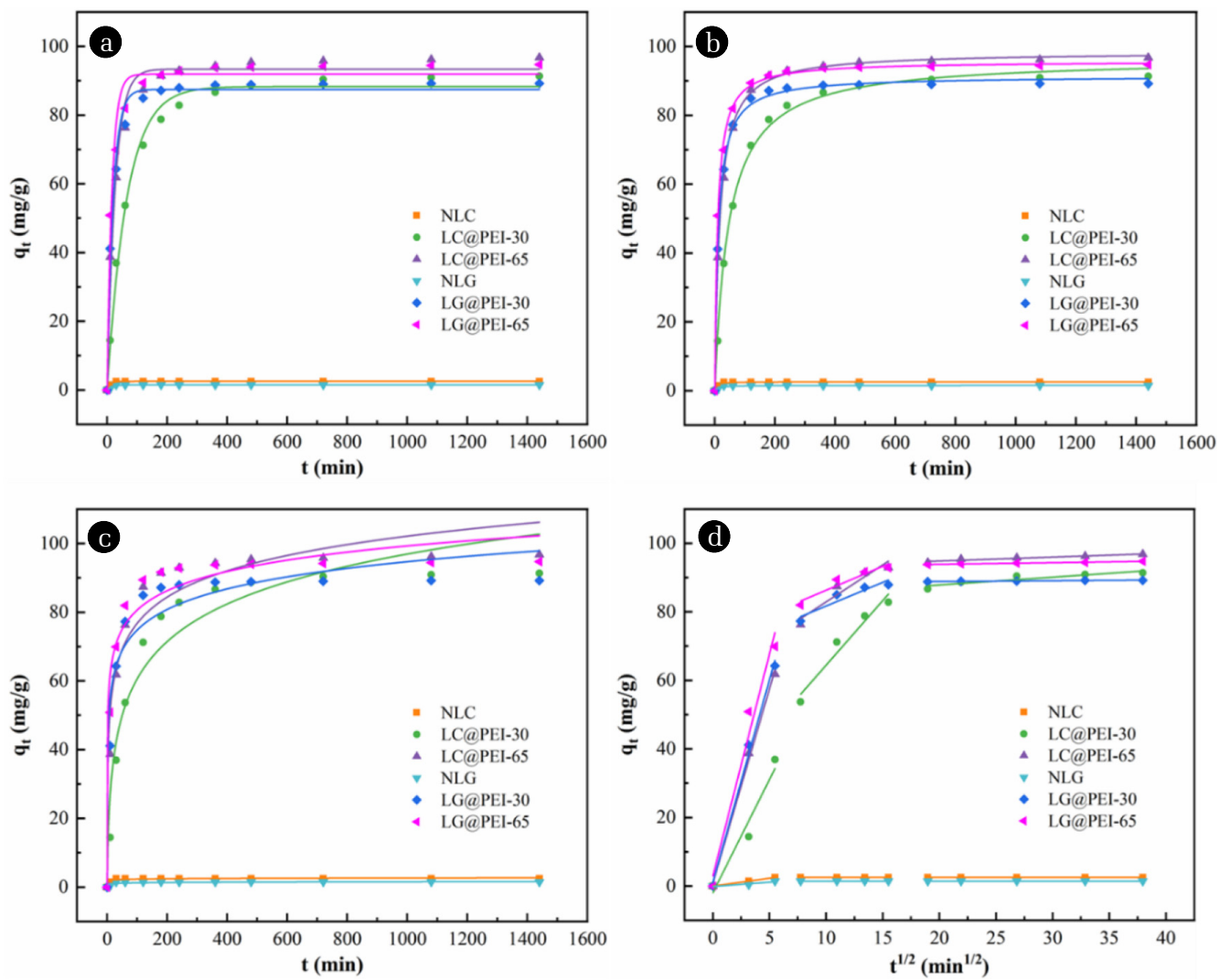

Fig. 4. Fitting lines of (a) Pseudo-first-order, (b) Pseudo-second-order, (c) Elovich and (d) intra-particle diffusion kinetic models for MO adsorption.

it could be discovered that the experimental data fitted better with pseudo-second order kinetic model due to the higher $\mathrm{R}^{2}$ value. This result supported the hypothesis that the rate-determining step of MO adsorption by modified pericarps was chemical adsorption [60]. In addition, the Elovich kinetic model is used to describe the adsorption behavior on heterogeneous solid adsorbents [61]. The high $\mathrm{R}^{2}$ value of Elovich model (0.944, 0.947, 0.937, 0.957 for LC@PEI-30, LC@PEI-65, LG@PEI-30 and LG@PEI-65, respectively) indicated that the adsorption sites on modified pericarps was inhomogeneous [43].

The intra-particle diffusion model can explain the diffusion mechanism of MO on the modified pericarps. The intra-particle diffusion model could represent different stages of the adsorption via multiple linear relationships [62]. The fitting for intra-particle diffusion kinetics of MO was shown in Fig. 4(d), where the fitting curve divided into three segments. The first stage (boundary layer diffusion) had the fastest adsorption rate due to the rapid diffusion of MO molecules from solution to the outer surface of the pericarps. During the second stage (internal diffusion), the MO molecules migrated from the outer surface to inner channel of pericarps. In this stage, the adsorption rate decreased and intra-particle diffusion was the rate-limiting step [63]. At the final stage (equilibrium stage), the diffusion rate was controlled by pore diffusion. For all modified pericarps, no line fitting the model pass through the origin (the $C_{i}$ value of all fitting line was not equal to zero), indicating that other adsorption process existed besides intra-particle diffusion. the diffusion of boundary layer was rate-limiting step since the value of $K_{1}$ was much higher than $K_{2}$ and $K_{3}$ [46]. Besides, the equilibrium adsorption capacity of pericarps promoted after PEI modification which mainly due to the enhancement of electrostatic interaction between MO molecules caused by the introduction of amines and imines and strongly diffusion interaction result from concentration gap.

For further researching the influence of solid-liquid ratio on the adsorption process, LC@PEI-65 was used for MO adsorption at initial concentrations of 10, 20 and $50 \mathrm{mg} / \mathrm{L}$. Instead of single linear fitting, multi-stage linear was suitable for describing the complicated adsorption process with multiple steps (Fig. 5(a), (b)). The intra-particle diffusion was included in adsorption process but not the exclusive rate-determining step due to the fitting straight line of each stage did not pass through the origin. In another word, the adsorption rate was controlled by both internal and external diffusion, electrostatic attraction, complexation and ion exchange may also influence the adsorption rate [64]. The values of $K_{i}$ and $C_{i}$ of step $i$ calculated from the slope and intercept of linear fitting for different modified pericarps were shown in Fig. 5(c) and Table S3. At the same MO concentration, it was observed that the reaction rate $\left(K_{i}\right)$ decreased while the thickness of the boundary $\left(C_{i}\right)$ layer increased as the reaction goes on. In the same step, the reaction rate and the boundary layer thickness increased with higher MO concentration which illustrating that lager concentration gap was conducive to the form of boundary layer and accelerated the adsorp- 

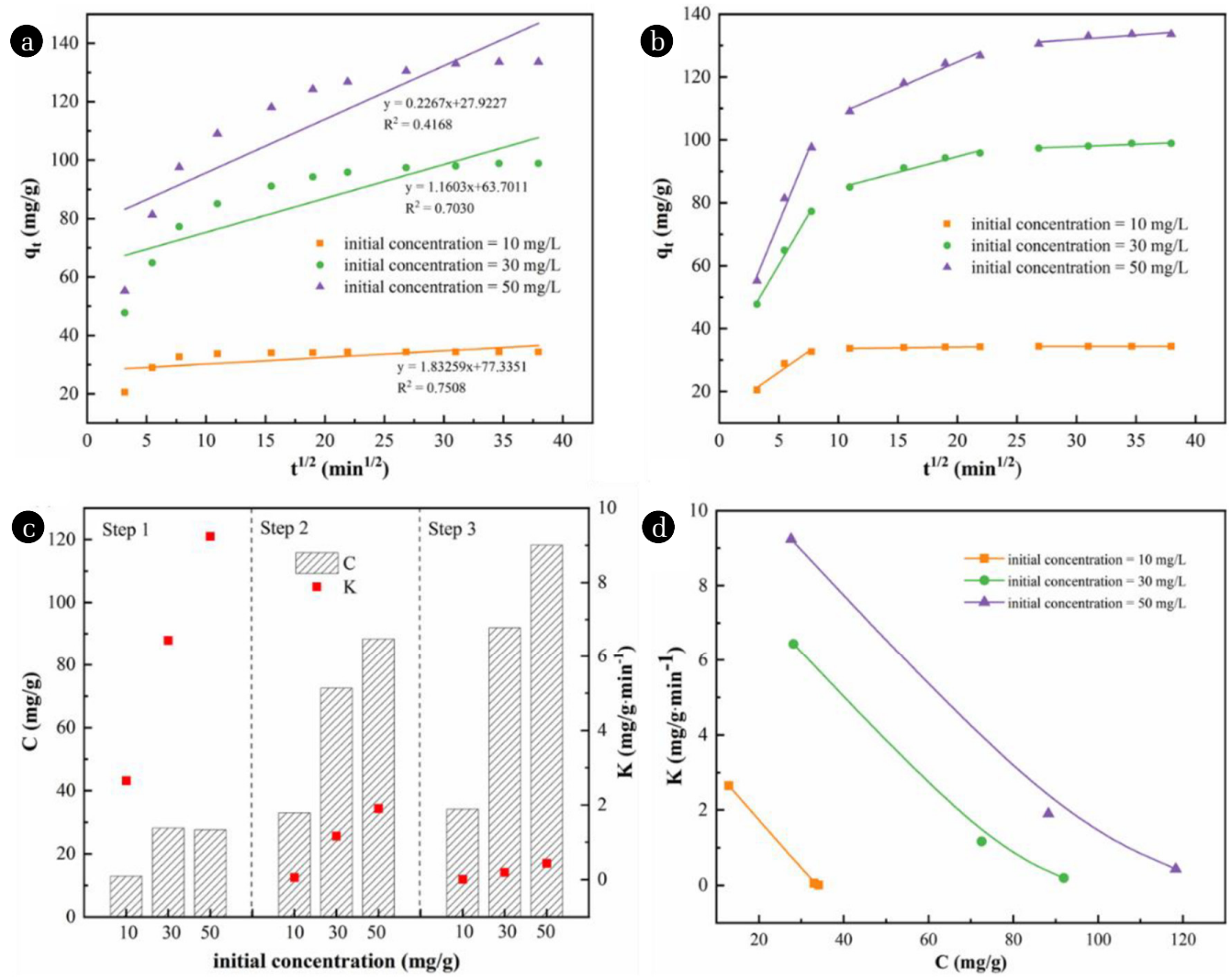

Fig. 5. Linear fitting (a), (b), value of $K$ and $C$ (c), and relationship between $K$ and $C$ (d) of intra-particle diffusion model.

tion rate. The boundary layer could be regarded as a viscous drag existed in the process of MO diffusing across to adsorbents surface [65]. The inverse correlation of $K$ against $C$ (Fig. 5(d)) suggested that the higher boundary layer thickness meant higher adsorption capacities.

\subsection{Adsorption Isotherm Evaluation}

Adsorption equilibrium isotherm is another key step to understand the adsorption mechanism and determine the most effective adsorbent for MO removal [66]. Nonlinear form of Langmuir, Freundlich, Temkin and D-R isotherm model were used to imitate the experimental data, the result was shown in Fig. 6 and Table S4. Obviously, increasing modification temperature from $30^{\circ} \mathrm{C}$ to $65^{\circ} \mathrm{C}$ was in favour of the adsorption capacity. For modified peri- carps, the highest $\mathrm{R}^{2}$ of Freundlich isotherm model implying that the removal process was mainly dominated by irregular multilayer adsorption with a large proportion of heterogeneous adsorption sites. The $K_{F}$ value indicated that the interaction strength between MO molecules and modified pericarps, a higher $K_{F}$ value mean a higher affinity [67]. The $K_{F}$ value of LC@PEI-65, LG@PEI-65, LC@PEI-30 and LG@PEI-65 were calculated as $84.504 \mathrm{~L} / \mathrm{mg}, 70.722 \mathrm{~L} / \mathrm{mg}, 53.693 \mathrm{~L} / \mathrm{mg}$ and $43.707 \mathrm{~L} / \mathrm{mg}$ respectively indicating the excellent adsorption performance of LC@PEI-65. In addition, the value of $n$ reflected the adsorption strength. When the value of $1 / n$ was in the range of $0.1-0.5$, the adsorption reaction occurs easily. However, the reaction is difficult to proceed when the value of $1 / n$ exceeds 1 [68]. In this study, the $1 / n$ values of all modified pericarps were lower

Table 1. Comparison of LC@PEI-65 with the Maximum MO Adsorption Capacities of Other Agricultural Waste Adsorbents

\begin{tabular}{lccc}
\hline Adsorbent & pH & Adsorption capacity (mg/g) & Reference \\
\hline Acetic acid treated Peanut husk & 2 & 79.7 & {$[69]$} \\
Modified Aloe Vera leaves activated carbon & 3 & 196.07 & {$[70]$} \\
CPC modified commercial coffee waste & 3.5 & 62.5 & {$[71]$} \\
Furfural industrial processing waste & 2 & 54.95 & {$[72]$} \\
Shaddock peels-based activated carbon & 3 & 94.59 & {$[73]$} \\
PANI-coated kapok fiber & natural & 136.75 & {$[74]$} \\
LC@PEI-65 & 4 & 349.37 & This study \\
\hline
\end{tabular}



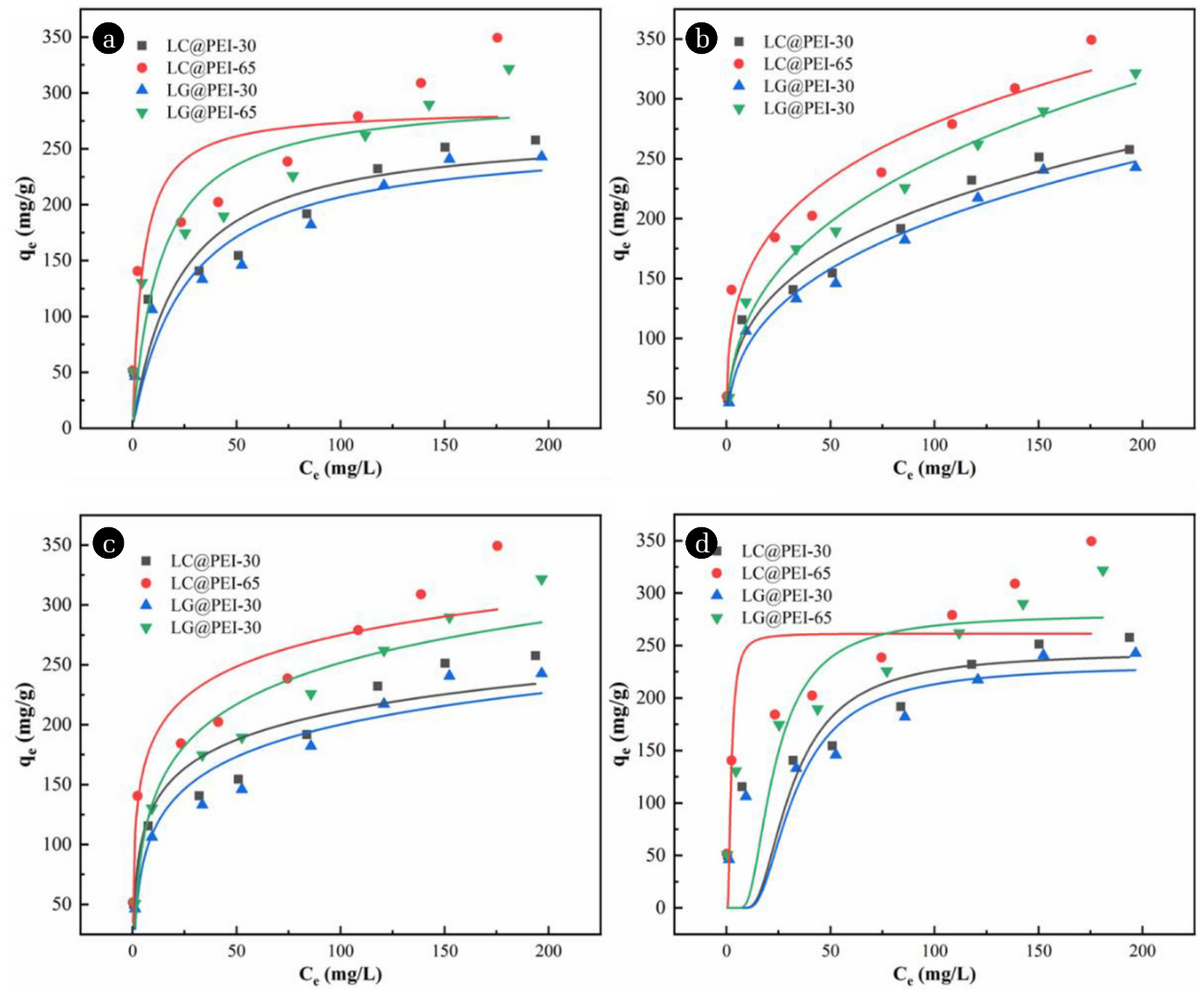

Fig. 6. Fitting lines of Langmuir (a), Freundlich (b), Temkin (c) and D-R (d) isotherm models for MO adsorption.

than 0.3 , indicating that the adsorption process of $\mathrm{MO}$ by modified pericarps were easy to occur. Interestingly, LC@PEI-65 adsorbent exhibited an excellent adsorption capacity when compared to previously reported adsorbents based on agricultural wastes (Table 1), which indicated LC@PEI-65 is a potential material for MO removal from wastewater.

\subsection{Regeneration and Reusability}

From the point of economic and environmental, the regeneration and reusability of the adsorbent are important for potential practical application [75]. After adsorption-desorption process up to five consecutive cycles using $0.1 \mathrm{~mol} / \mathrm{L}$ sodium hydroxide solution, the desorption rates of MO still reached $92.78 \%$ (Fig. $\mathrm{S} 2$ ). In the meantime, the removal rate of $\mathrm{MO}$ by recycled LC@PEI-65 remained above 95\% after five cycles. Therefore, modified pericarps could be used for MO removal as an efficient and reusable adsorbent.

\subsection{Adsorption Mechanism}

The adsorption of MO by modified pericarps was a complex process, where many different types of interactions may exist simultaneously. Based on the above research, four potential adsorption mechanisms were proposed in Fig. 7. The main adsorption mechanism was the electrostatic attraction between negatively charged sulfonic groups of $\mathrm{MO}$ molecules and protonated amines and imines on modified pericarps. Moreover, the $\mathrm{H}$ in the hydroxyl and carboxyl groups on modified pericarps can form intermolecular hydrogen bonds with the $\mathrm{N}$ of $\mathrm{MO}$. The $\mathrm{H}$ in the amine group on modified pericarps can also form a hydrogen bond with the $\mathrm{O}$ in $\mathrm{MO}$ molecules, which can enhance the removal of $\mathrm{MO}$ from wastewater [76]. Additionally, the $\pi-\pi$ dispersion interaction existed between the aromatic ring of $\mathrm{MO}$ molecules and the aromatic ring in the modified pericarps. Finally, the diffusion of $\mathrm{MO}$ in the internal channel of pericarps can be also one of the adsorption mechanisms. In summary, electrostatic interaction, intermolecular hydrogen bond, $\pi-\pi$ dispersion interaction and pore filling collectively explained the observed adsorption perfomance.

\subsection{Cost Analysis}

In general, the cost of adsorption process for dye removal is predominantly depended on the cost of adsorbent and its regeneration [77]. Based on the on the method described by Mashile and Nordin $\mathrm{AH}[78,79]$, the cost estimation breakdown for the preparation of LC@PEI-65 was presented in Table S5. Comparing to other commercially adsorbents, such as activated carbon (Charcoal, Activated Coconut, EMD Chemicals; \$145/kg), ion-exchange resin (Dowex(r) 50WX8-100; $\$ 390 / \mathrm{kg}$ ] [80], the cost of LC@PEI-65 is much cheaper. A kilogram of the prepared LC@PEI-65 costs nearly CNY94.358(\$14). Subsequently, the cost of LC@PEI-65 was further reduced due to its high adsorption capacity (349.37 mg/g) and 


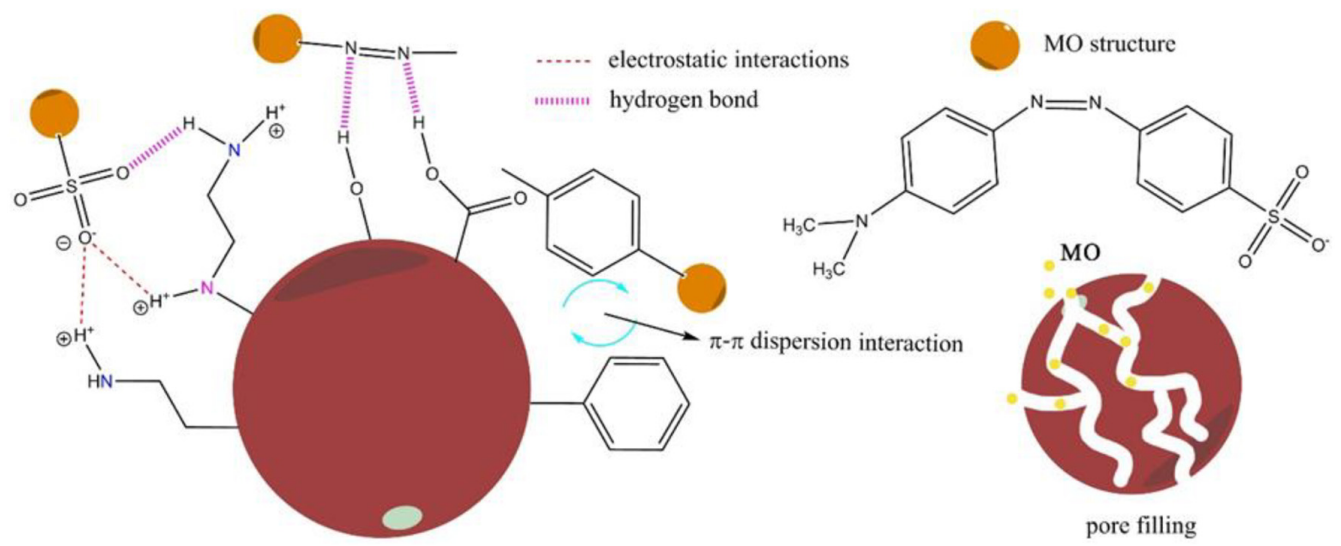

Fig. 7. Adsorption mechanism of $\mathrm{MO}$ on PEI thermochemical modified pericarps.

good regeneration performance, since one batch can be reused at least five times. Hence, LC@PEI-65 is an economical material, following the simplicity of synthesis process and high adsorption capacity.

\section{Conclusions}

In conclusion, an uncomplicated modification with PEI was triumphantly enhanced the adsorption capacity of lychee and longan pericarps. The maximum adsorption capacity of LC@PEI-65 reached $349.37 \mathrm{mg} / \mathrm{g}$ under the optimal $\mathrm{pH}$ value of 4 and the suitable temperature of $45^{\circ} \mathrm{C}$. The characterization of modified pericarps by XRD, FTIR, Zeta potential and SEM analysis confirmed the successful introduction of amino and imino groups. Furthermore, the kinetic and isotherm researches illustrated that the MO adsorption by modified pericarps fitted well with the pseudo-second order and Freundlich model. It could be found that MO removal by modified pericarps was a complicated process including electrostatic interaction, intermolecular hydrogen bonding, $\pi-\pi$ dispersion interaction and pore filling. This study demonstrated that LC@PEI-65 is an efficient, low-cost, and renewable adsorbent for the removal of azo dyes such as $\mathrm{MO}$ from aqueous solutions.

\section{Acknowledgments}

This research was financially supported by the National Natural Science Foundation of China (41977114), Guangdong Basic and Applied Basic Research Foundation of China (2020A1515011113), and Guangzhou Science and Technology Project of China (202002030455).

\section{Author Contributions}

J.Z.M (Master student) conducted all the experiments and wrote the manuscript. S.M.Z (bachelor student) did a little analysis. L.Y.H (Ph.D) and X.Y.Z (Master) helped revised the manuscript. P.L
(Professor) led the overall study as a corresponding author.

\section{References}

1. Tee PF, Abdullah MO, Tan IAW, et al. Review on hybrid energy systems for wastewater treatment and bio-energy production. Renew. Sust. Energy Reviews. 2016;54:235-246.

2. Carstea EM, Bridgeman J, Baker A, Reynolds DM. Fluorescence spectroscopy for wastewater monitoring: A review. Water Res. 2016;95:205-219.

3. Gheju M, Balcu I, Mosoarca G. Removal of Cr(VI) from aqueous solutions by adsorption on $\mathrm{MnO}_{2}$. J. Hazard. Mater. 2016;310: 270-277.

4. Sen SK, Raut S, Bandyopadhyay P, Raut S. Fungal decolouration and degradation of azo dyes: A review. Fungal Biol. Rev. 2016;30: 112-133.

5. Bhatnagar A, Jain AK. A comparative adsorption study with different industrial wastes as adsorbents for the removal of cationic dyes from water. J. Colloid. Interface. Sci. 2005;281: 49-55.

6. Ye L, Xu H, Zhang D, Chen S. Synthesis of bilayer MoS2 nanosheets by a facile hydrothermal method and their methyl orange adsorption capacity. Mater. Res. Bulletin. 2014;55:221-228.

7. Jobby R, Jha P, Yadav AK, Desai N. Biosorption and biotransformation of hexavalent chromium [Cr(VI)]: A comprehensive review. Chemosphere 2018;207:255-266.

8. Katheresan V, Kansedo J, Lau SY. Efficiency of various recent wastewater dye removal methods: A review. J. Environ. Chem. Eng. 2018;6:4676-4697.

9. Zhou Y, Fang X, Wang T, Hu Y, Lu J. Chelating agents enhanced $\mathrm{CaO}_{2}$ oxidation of bisphenol A catalyzed by $\mathrm{Fe}^{3+}$ and reuse of ferric sludge as a source of catalyst. Chem. Eng. J. 2017;313:638-645.

10. Wang J, Wang X, Zhao G, et al. Polyvinylpyrrolidone and polyacrylamide intercalated molybdenum disulfide as adsorbents for enhanced removal of chromium(VI) from aqueous solutions. Chem. Eng. J. 2018;334:569-578.

11. Bilal M, Shah JA, Ashfaq T, et al. Waste biomass adsorbents for copper removal from industrial wastewater-A review. J. Hazard. Mater. 2013;263:322-333. 
12. Fu F, Wang Q. Removal of heavy metal ions from wastewaters: A review. J. Environ. Manage. 2011;92:407-418.

13. Dotto GL, Santos JMN, Tanabe EH, et al. Chitosan/polyamide nanofibers prepared by Forcespinning ${ }^{\circledR}$ technology: A new adsorbent to remove anionic dyes from aqueous solutions. J. Clean. Prod. 2017;144:120-129.

14. Giannakoudakis DA, Kyzas GZ, Avranas A, Lazaridis NK. Multi-parametric adsorption effects of the reactive dye removal with commercial activated carbons. J. Mol. Liq. 2016;213: 381-389.

15. Lu F, Dong A, Ding G, Xu K, Li J, You L. Magnetic porous polymer composite for high performance adsorption of acid red 18 based on melamine resin and chitosan. J. Mol. Liq. 2019;294:111515.

16. Sivalingam S, Sen S. Efficient removal of textile dye using nanosized fly ash derived zeolite-x: Kinetics and process optimization study. J. Taiwan Inst. Chem. Eng. 2019;96:305-314.

17. Chaari I, Fakhfakh E, Medhioub M, Jamoussi F. Comparative study on adsorption of cationic and anionic dyes by smectite rich natural clays. J. Mol. Struct. 2019;1179:672-677.

18. Adegoke KA, Bello OS. Dye sequestration using agricultural wastes as adsorbents. Water Resour. Ind. 2015;12:8-24.

19. Cheruiyot GK, Wanyonyi WC, Kiplimo JJ, Maina EN. Adsorption of toxic crystal violet dye using coffee husks: Equilibrium, kinetics and thermodynamics study. Scientific African. 2019;5: e00116.

20. Bulgariu L, Escudero LB, Bello OS, et al. The utilization of leaf-based adsorbents for dyes removal: A review. J. Mol. Liq. 2019;276:728-747.

21. Cengiz S, Tanrikulu F, Aksu S. An alternative source of adsorbent for the removal of dyes from textile waters: Posidonia oceanica (L.). Chem. Eng. J. 2012;189-190:32-40.

22. Argun ME, Güclü D, Karatas M. Adsorption of Reactive Blue 114 dye by using a new adsorbent: Pomelo peel. J. Ind. Eng. Chem. 2014;20:1079-1084.

23. Singh S, Parveen N, Gupta H. Adsorptive decontamination of rhodamine-B from water using banana peel powder: A biosorbent. Environ. Technol. Innov. 2018;12:189-195.

24. Temesgen F, Gabbiye N, Sahu O. Biosorption of reactive red dye (RRD) on activated surface of banana and orange peels: Economical alternative for textile effluent. Surf. Interfaces. 2018;12:151-159.

25. Jiang R, Tian J, Zheng H, Qi J, Sun S, Li X. A novel magnetic adsorbent based on waste litchi peels for removing $\mathrm{Pb}(\mathrm{II})$ from aqueous solution. J. Environ. Manage. 2015;155:24-30.

26. Li L, Cao G, Zhu R. Adsorption of Cr(VI) from aqueous solution by a litchi shell-based adsorbent. Environ. Res. 2020:110356.

27. Yi Y, Lv J, Liu Y, Wu G. Synthesis and application of modified Litchi peel for removal of hexavalent chromium from aqueous solutions. J. Mol. Liq. 2017;225:28-33.

28. Zheng H, Qi J, Jiang R, Gao Y, Li X. Adsorption of malachite green by magnetic litchi pericarps: A response surface methodology investigation. J. Environ. Manage. 2015;162:232-239.

29. Wang Y, Zhu L, Jiang H, Hu F, Shen X. Application of longan shell as non-conventional low-cost adsorbent for the removal of cationic dye from aqueous solution. Spectrochim. Spectrochimica. Acta. Part A. 2016;159:254-261.
30. Nagle M, Habasimbi K, Mahayothee B, Haewsungcharern M, Janjai S, Müller J. Fruit processing residues as an alternative fuel for drying in Northern Thailand. Fuel 2011;90:818-823.

31. Nayak AK, Pal A. Statistical modeling and performance evaluation of biosorptive removal of Nile blue A by lignocellulosic agricultural waste under the application of high-strength dye concentrations. J. Environ. Chem. Eng. 2020;8:103677.

32. Wang X, Liu Q, Liu J, et al. 3D self-assembly polyethyleneimine modified graphene oxide hydrogel for the extraction of uranium from aqueous solution. Appl. Surf. Sci. 2017;426:1063-1074.

33. Wang J, Cao M, Jiang C, Zheng Y, Zhang C, Wei J. Adsorption and coadsorption mechanisms of $\mathrm{Hg}^{2+}$ and methyl orange by branched polyethyleneimine modified magnetic straw. Mater. Lett. 2018;229:160-163.

34. Jiang Q, Xie W, Han S, Wang Y, Zhang Y. Enhanced adsorption of $\mathrm{Pb}$ (II) onto modified hydrochar by polyethyleneimine or $\mathrm{H}_{3} \mathrm{PO}_{4}$ : An analysis of surface property and interface mechanism. Colloids. Surf. A: Physicochem. Eng. Asp. 2019;583:123962.

35. Mashkoor F, Nasar A. Preparation, characterization and adsorption studies of the chemically modified Luffa aegyptica peel as a potential adsorbent for the removal of malachite green from aqueous solution. J. Mol. Liq. 2019;274:315-327.

36. Franco DSP, Cunha JM, Dortzbacher GF, Dotto GL. Adsorption of Co(II) from aqueous solutions onto rice husk modified by ultrasound assisted and supercritical technologies. Process Saf. Environ. Protection. 2017;109:55-62.

37. Mondal S, Majumder SK. Honeycomb-like porous activated carbon for efficient copper (II) adsorption synthesized from natural source: Kinetic study and equilibrium isotherm analysis. J. Environ. Chem. Eng. 2019;7:103236.

38. Kim Y-S, Kim J-H. Isotherm, kinetic and thermodynamic studies on the adsorption of paclitaxel onto Sylopute. J. Chem. Thermodyn. 2019;130:104-113.

39. Mobarak M, Mohamed EA, Selim AQ, et al. Statistical physics modeling and interpretation of methyl orange adsorption on high-order mesoporous composite of MCM-48 silica with treated rice husk. J. Mol. Liq. 2019;285:678-687.

40. Kumari S, Mahapatra S, Das S. Ca-alginate as a support matrix for $\mathrm{Pb}(\mathrm{II})$ biosorption with immobilized biofilm associated extracellular polymeric substances of Pseudomonas aeruginosa N6P6. Chem. Eng. J. 2017;328:556-566.

41. Jing Y, Gao H, Yang C-Y. Chitosan microspheres modified with poly( ethylenimine) enhance the adsorption of methyl orange from aqueous solutions. Asia-Pacific J. Chem. Eng. 2016;11: 428-436.

42. Wang X, Feng J, Cai Y, et al. Porous biochar modified with polyethyleneimine (PEI) for effective enrichment of U(VI) in aqueous solution. Sci. Total Environ. 2020;708:134575.

43. Jiang Z, Hu D. Molecular mechanism of anionic dyes adsorption on cationized rice husk cellulose from agricultural wastes. J. Mol. Liq. 2019;276:105-114.

44. Witek-Krowiak A, Harikishore Kumar Reddy D. Removal of microelemental $\mathrm{Cr}(\mathrm{III})$ and $\mathrm{Cu}$ (II) by using soybean meal waste - Unusual isotherms and insights of binding mechanism. Bioresour. Technol. 2013;127:350-357.

45. Huang Z, Huang Z, Feng L, et al. Modified cellulose by polyethyleneimine and ethylenediamine with induced $\mathrm{Cu}(\mathrm{II})$ and 
$\mathrm{Pb}(\mathrm{II})$ adsorption potentialities. Carbohyd. Polym. 2018;202: 470-478.

46. Fan H, Ma Y, Wan J, Wang Y, Li Z, Chen Y. Adsorption properties and mechanisms of novel biomaterials from banyan aerial roots via simple modification for ciprofloxacin removal. Sci. Total Environ. 2020;708:134630.

47. Peng W, Xie Z, Cheng G, Shi L, Zhang Y. Amino-functionalized adsorbent prepared by means of $\mathrm{Cu}(\mathrm{II})$ imprinted method and its selective removal of copper from aqueous solutions. J. Hazard. Mater. 2015;294:9-16.

48. Sadaf S, Bhatti HN, Nausheen S, Amin M. Application of a novel lignocellulosic biomaterial for the removal of Direct Yellow 50 dye from aqueous solution: Batch and column study. J. Taiwan Inst. Chem. Eng. 2015;47:160-170.

49. Kismir Y, Aroguz AZ. Adsorption characteristics of the hazardous dye Brilliant Green on Saklıkent mud. Chem. Eng. J. 2011;172:199-206.

50. Huang R, Liu Q, Huo J, Yang B. Adsorption of methyl orange onto protonated cross-linked chitosan. Arabian J. Chem. 2017;10:24-32.

51. Wong S, Tumari HH, Ngadi N, et al. Adsorption of anionic dyes on spent tea leaves modified with polyethyleneimine (PEI-STL). J. Clean. Prod. 2019;206:394-406.

52. Lian F, Song Z, Liu Z, Zhu L, Xing B. Mechanistic understanding of tetracycline sorption on waste tire powder and its chars as affected by $\mathrm{Cu}^{2+}$ and pH. Environ. Pollut. 2013;178:264-270.

53. Kang S, Qin L, Zhao Y, et al. Enhanced removal of methyl orange on exfoliated montmorillonite/chitosan gel in presence of methylene blue. Chemosphere 2020;238:124693.

54. Lu Y, Fan L, Yang L-Y, Huang F, Ouyang X-k. PEI-modified core-shell/bead-like amino silica enhanced poly (vinyl alcohol)/chitosan for diclofenac sodium efficient adsorption. Carbohyd. Polym. 2020;229:115459.

55. Jiang X, An Q-D, Xiao Z-Y, Zhai S-R, Shi Z. Mussel-inspired surface modification of untreated wasted husks with stable polydopamine/polyethylenimine for efficient continuous $\mathrm{Cr}(\mathrm{VI})$ removal. Mater. Res. Bull. 2018;102:218-225.

56. Yuvaraja G, Chen D-Y, Pathak JL, et al. Preparation of novel aminated chitosan schiff's base derivative for the removal of methyl orange dye from aqueous environment and its biological applications. Int. J. Biol. Macromol. 2020;146:1100-1110.

57. Jiang T, Liang Y-d, He Y-j, Wang Q. Activated carbon/ $/ \mathrm{NiFe}_{2} \mathrm{O}_{4}$ magnetic composite: A magnetic adsorbent for the adsorption of methyl orange. J. Environ. Chem. Eng. 2015;3:1740-1751.

58. Tran VA, Kadam AN, Lee S-W. Adsorption-assisted photocatalytic degradation of methyl orange dye by zeolite-imidazole-framework-derived nanoparticles. J. Alloys Compd. 2020;835: 155414.

59. Zhao B, Sun X, Wang L, Zhao L, Zhang Z, Li J. Adsorption of methyl orange from aqueous solution by composite magnetic microspheres of chitosan and quaternary ammonium chitosan derivative. Chinese J. Chem. Eng. 2019;27:1973-1980.

60. Kumar KV, Ramamurthi V, Sivanesan S. Modeling the mechanism involved during the sorption of methylene blue onto fly ash. J. Colloid. Interf. Sci. 2005;284:14-21.

61. Jiang ZH, Hu DY. Molecular mechanism of anionic dyes adsorption on cationized rice husk cellulose from agricultural wastes.
J. Mol. Liq. 2019;276:105-114.

62. Sun Q, Yang L. The adsorption of basic dyes from aqueous solution on modified peat-resin particle. Water Res. 2003;37: 1535-1544.

63. Gupta VK, Ali I, Suhas, Mohan D. Equilibrium uptake and sorption dynamics for the removal of a basic dye (basic red) using low-cost adsorbents. J. Colloid. Interf. Sci. 2003;265: 257-264.

64. Park HN, Choi HA, Won SW. Fibrous polyethylenimine/polyvinyl chloride crosslinked adsorbent for the recovery of Pt(IV) from acidic solution: Adsorption, desorption and reuse performances. J. Clean. Prod. 2018;176:360-369.

65. Toor M, Jin B. Adsorption characteristics, isotherm, kinetics, and diffusion of modified natural bentonite for removing diazo dye. Chem. Eng. J. 2012;187:79-88.

66. Ibrahim RK, El-Shafie A, Hin LS, et al. A clean approach for functionalized carbon nanotubes by deep eutectic solvents and their performance in the adsorption of methyl orange from aqueous solution. J. Environ. Manage. 2019;235:521-534.

67. Song J, Zhang S, Li G, Du Q, Yang F. Preparation of montmorillonite modified biochar with various temperatures and their mechanism for Zn ion removal. J. Hazard. Mater. 2020;391: 121692.

68. Peng S, Mao T, Zheng C, et al. Polyhydroxyl gemini surfactant-modified montmorillonite for efficient removal of methyl orange. Colloids Surf. A. Physicochem. Eng. Asp. 2019;578: 123602.

69. Sadaf S, Bhatti HN. Batch and fixed bed column studies for the removal of Indosol Yellow BG dye by peanut husk. J. Taiwan Inst. Chem. Eng. 2014;45:541-553.

70. Khaniabadi YO, Heydari R, Nourmoradi H, Basiri H, Basiri H. Low-cost sorbent for the removal of aniline and methyl orange from liquid-phase: Aloe Vera leaves wastes. J. Taiwan Inst. Chem. Eng. 2016;68:90-98.

71. Lafi R, Hafiane A. Removal of methyl orange (MO) from aqueous solution using cationic surfactants modified coffee waste (MCWs). J. Taiwan Inst. Chem. Eng. 2016;58:424-433.

72. Chen XY, Li HP, Liu WY, et al. Effective removal of methyl orange and rhodamine $\mathrm{B}$ from aqueous solution using furfural industrial processing waste: Furfural residue as an eco-friendly biosorbent. Colloid. Surface A. 2019;583:123976.

73. Tao XM, Wu YH, Cha LG. Shaddock peels-based activated carbon as cost-saving adsorbents for efficient removal of Cr (VI) and methyl orange. Environ. Sci. Pollut. R. 2019;26:19828-19842.

74. Gapusan RB, Balela MDL. Adsorption of anionic methyl orange dye and lead(II) heavy metal ion by polyaniline-kapok fiber nanocomposite. Mater. Chem. Phys. 2020;243:122682.

75. Chen Y, Peng J, Xiao H, et al. Adsorption behavior of hydrotalcite-like modified bentonite for $\mathrm{Pb}^{2+}, \mathrm{Cu}^{2+}$ and methyl orange removal from water. Appl. Surf. Sci. 2017;420:773-781.

76. Fan S, Wang Y, Wang Z, Tang J, Tang J, Li X. Removal of methylene blue from aqueous solution by sewage sludge-derived biochar: Adsorption kinetics, equilibrium, thermodynamics and mechanism. J. Environ. Chem. Eng. 2017;5:601-611.

77. Li X, Wang Z, Ning J, et al. Preparation and characterization of a novel polyethyleneimine cation-modified persimmon tannin bioadsorbent for anionic dye adsorption. J. Environ. Manage. 
2018;217:305-314.

78. Nordin AH, Wong S, Ngadi N, et al. Surface functionalization of cellulose with polyethyleneimine and magnetic nanoparticles for efficient removal of anionic dye in wastewater. J. Environ. Chem. Eng. 2021;9(1):104639.

79. Mashile GP, Dimpe KM, Nomngongo PN. A Biodegradable Magnetic Nanocomposite as a Superabsorbent for the
Simultaneous Removal of Selected Fluoroquinolones from Environmental Water Matrices: Isotherm, Kinetics, Thermodynamic Studies and Cost Analysis. Polymers (Basel). 2020;12:1102.

80. Argun ME, Dursun S, Karatas M. Removal of Cd(II), Pb(II), $\mathrm{Cu}(\mathrm{II})$ and $\mathrm{Ni}(\mathrm{II})$ from water using modified pine bark. Desalination 2009;249:519-527. 